\title{
Thermoelasticity of Polymer Networks
}

\section{William W. Graessley*,t}

Department of Chemical Engineering, Princeton University, Princeton, New J ersey 08544

\author{
Lewis J . Fetters ${ }^{\ddagger}$
}

Institut für Festkörperforschung, Forschungszentrum J ülich, D-52425 J ülich, Germany

Received J une 8, 2001; Revised Manuscript Received J uly 25, 2001

\begin{abstract}
The thermoelastic properties of polymer networks are of interest owing to the information they provide on $\kappa=d \ln \left\langle\mathrm{R}^{2}\right\rangle_{0} / \mathrm{dT}$, the temperature coefficient of chain dimensions of the network species. Stress-strain measurements at constant volume provide that information directly, through a determination of the energetic fraction of the restoring force $f_{e} / f$. Almost always, however, the measurements are conducted under constant-pressure conditions, and a correction is applied to account for the effect of volume change. The correction formula commonly used is known to be inaccurate, and here we present a new one that predicts the volume change and $\kappa$ quite satisfactorily. Some comparisons of $\kappa$ obtained from thermoelastic measurements, from small-angle neutron scattering, and from intrinsic viscosity data in athermal solvents are given.
\end{abstract}

\section{Introduction}

The thermoelastic properties of polymer networks have been studied intensively over the years. Molecular theories based on the random coil model predict the temperature dependence of stress-strain behavior and testing that prediction to verify the model was an early interest. A later interest was to use the data and model to obtain $\kappa=\mathrm{d} \mid \mathrm{n}\left\langle\mathrm{R}^{2}\right\rangle_{0} / \mathrm{dT}$, the temperature coefficient of chain dimensions for the network species. Its value depends on local molecular structure and the energy differences among rotational isomeric states and therefore is of interest in the molecular theory of chain conformations. ${ }^{1}$ Before small-angle neutron scattering became available, $\kappa$ was not easily obtained by other means. Some aspects of the analysis of thermoelastic data were left unsettled, however. This article offers a clarification and corresponding correction of $\kappa$ for various species.

\section{Development}

When stress is applied to an elastic body, the effect at equilibrium is to store elastic energy in the body by changing both its shape and its volume. For uniaxial tension applied to an elastomeric network at ambient pressure, the elastic energy results from both network distortion and volume dilatation. Adopting the J amesGuth view, ${ }^{2}$ these can be regarded as the independent contributions of two entities cohabiting the occupied space. One is a volumeless network of random-coil strands that undergoes a global extension. The other is a dense liquid that is caused to expand by the uniaxial tension acting upon it. Only the network contribution is of interest in the consideration of molecular elasticity theory. It can be obtained either by stress-strain experiments conducted at constant volume, which are difficult in practice, or by constant pressure experiments, which are relatively easy, and then correcting

† Permanent address: 7496 Old Channel Trail, Montague, MI 49437.

₹ Permanent address: Chemical Engineering Department, Cornell University, Ithaca, NY 14853. for the dilatation. It is the widely used correction formula that is of concern here.

The development here draws extensively on results reported in the review of thermoelasticity by Price. $^{3}$ Whether constant-pressure or constant-vol ume experiments are conducted, the equilibrium restoring force $f$ in uniaxial extension is measured as a function of specimen length $L$ and temperature $T$. The energetic and entropic components of the force, $f_{e}(L, T)$ and $f_{s}(L, T)$, are obtained from derivatives of the force with respect to temperature. 3,4 Thus, for constant-pressure experiments,

$$
\left(\frac{\partial \mathrm{H}}{\partial \mathrm{L}}\right)_{\mathrm{P}, \mathrm{T}}=-\left(\frac{\partial(\mathrm{f} / \mathrm{T})}{\partial(1 / \mathrm{T})}\right)_{\mathrm{P}, \mathrm{L}}
$$

and for constant-volume experiments,

$$
\left(\frac{\partial U}{\partial L}\right)_{V, T}=-\left[\frac{\partial(f / T)}{\partial(1 / T)}\right]_{V, L}=f_{e}(L, T)
$$

in which $\mathrm{U}$ and $\mathrm{H}$ are the internal energy and enthalpy of the specimen, and $f_{s}=f-f_{e}$. Only the network contribution, the energetic fraction of force $f_{e} / f$ at constant volume, is of interest:

$$
\frac{f_{e}}{f}=1-\frac{T}{f}\left(\frac{\partial f}{\partial T}\right)_{V, T}
$$

The difference between $(\partial \mathrm{H} / \partial \mathrm{L})_{P, T}$ and $(\partial \mathrm{U} / \partial \mathrm{L})_{P, T}$ is negligible at ambient pressures for systems with dense liquid compressibility. The constant-pressure strain can be expressed as the sum of a constant-volume strain and then a dilatation at constant strain to the final volume. The result is a correction formula: ${ }^{5}$

$$
\left(\frac{\partial \mathrm{U}}{\partial \mathrm{L}}\right)_{\mathrm{V}, \mathrm{T}}=\left(\frac{\partial \mathrm{H}}{\partial \mathrm{L}}\right)_{\mathrm{P}, \mathrm{T}}-\Delta_{\mathrm{P}, \mathrm{L}}
$$


in which

$$
\Delta_{P, L}=\left(\frac{\partial U}{\partial V}\right)_{L, T}\left(\frac{\partial \mathrm{V}}{\partial \mathrm{L}}\right)_{\mathrm{P}, \mathrm{T}}
$$

The first term on the right side is the internal pressure, shown by separate experiments to be independent of strain. ${ }^{6} \mathrm{~F}$ or dense liquids and ambient pressures, it is well approximated by

$$
\left(\frac{\partial \mathrm{U}}{\partial \mathrm{V}}\right)_{\mathrm{L}, \mathrm{T}}=\frac{\alpha \mathrm{T}}{\beta}
$$

in which $\alpha$ is the thermal expansion coefficient and $\beta$ the isothermal compressibility. The second term on the right side of eq $5,(\partial \mathrm{V} / \partial \mathrm{L})_{\mathrm{P}, \mathrm{T}}$, describes the dilatation. Flory developed an expression for the dilatation based on the Gaussian network model ${ }^{7}$

$$
\left(\frac{\partial \mathrm{V}}{\partial \mathrm{L}}\right)_{\mathrm{P}, \mathrm{T}}=\frac{\beta \mathrm{f}}{\lambda^{3}-1}
$$

in which $\lambda$ is the stretch ratio $L / L_{0}$. Equations 6 and 7 lead to the corresponding correction factor:

$$
\Delta_{\mathrm{P}, \mathrm{L}}=\frac{\alpha \mathrm{Tf}}{\lambda^{3}-1}
$$

Allen, Bianchi, and Price built an apparatus for making constant-volume thermoelastic measurements in uniaxial extension. ${ }^{6}$ They applied eq 3 to the data and obtained values of $f_{e} / f$ for several network species. Their results are summarized in ref 3 . The same apparatus was also designed to generate constantpressure and dilatation data for the same networks, permitting eqs $6-8$ to be tested independently. Their results and those of others ${ }^{4,8,9}$ showed that neither eq 7 nor eq 8 was adequate. Price ${ }^{3}$ pointed out, however, that much better agreement with the dilatation data was obtained when the thermodynamic consequences of an earlier proposal by $\mathrm{Gee}^{10}$

$$
(\partial \mathrm{L} / \partial \mathrm{P})_{\mathrm{f}, \mathrm{T}}=-\beta \mathrm{L} / 3
$$

were worked out. The following thermodynamic identities,

$$
\begin{gathered}
\left(\frac{\partial \mathrm{V}}{\partial \mathrm{L}}\right)_{\mathrm{P}, \mathrm{T}}=\left(\frac{\partial \mathrm{f}}{\partial \mathrm{P}}\right)_{\mathrm{L}, \mathrm{T}} \\
\left(\frac{\partial \mathrm{f}}{\partial \mathrm{P}}\right)_{\mathrm{L}, \mathrm{T}}=-\left(\frac{\partial \mathrm{f}}{\partial \mathrm{L}}\right)_{\mathrm{P}, \mathrm{T}}\left(\frac{\partial \mathrm{L}}{\partial \mathrm{P}}\right)_{\mathrm{f}, \mathrm{T}}
\end{gathered}
$$

together with the Gee proposal, lead to

$$
\left(\frac{\partial \mathrm{V}}{\partial \mathrm{L}}\right)_{\mathrm{P}, \mathrm{T}}=\frac{\beta \mathrm{L}}{3}\left(\frac{\partial \mathrm{f}}{\partial \mathrm{L}}\right)_{\mathrm{P}, T}=\frac{\beta \lambda}{3}\left(\frac{\partial \mathrm{f}}{\partial \lambda}\right)_{\mathrm{P}, T}
$$

The force can be expressed with the Gaussian network model: 4

$$
\frac{f}{A_{0}}=G_{0}\left(\lambda-\frac{1}{\lambda^{2}}\right)
$$

where $A_{0}$ is the undeformed cross section at the test temperature and $\mathrm{G}_{0}$ is the shear modulus. Applying that formula leads to the foll owing dilatation equation:

$$
\left(\frac{\partial \mathrm{V}}{\partial \mathrm{L}}\right)_{\mathrm{P}, \mathrm{T}}=\frac{\beta}{3} \frac{\lambda^{3}+2}{\lambda^{3}-1} \mathrm{f}
$$

A revised correction factor then follows immediately from eqs 5, 6, and 13:

$$
\Delta_{\mathrm{P}, \mathrm{L}}=\frac{\alpha \mathrm{T}}{3} \frac{\lambda^{3}+2}{\lambda^{3}-1} \mathrm{f}
$$

For completeness, we also include the result of replacing the Gaussian expression with the Mooney-Rivlin form: ${ }^{4}$

$$
\frac{\mathrm{f}}{\mathrm{A}_{0}}=\left(2 \mathrm{C}_{1}+\frac{2 \mathrm{C}_{2}}{\lambda}\right)\left(\lambda-\frac{1}{\lambda^{2}}\right)
$$

where $C_{1}$ and $C_{2}$ are empirical parameters that vary from one network to another. Assuming $C_{1}$ and $C_{2}$ have the same temperature dependence, eqs 11 and 15 lead to the Mooney-Rivlin variant:

$$
\Delta_{\mathrm{P}, \mathrm{L}}=\frac{\alpha \mathrm{T}}{3} \frac{\lambda^{4}+2 \lambda+3 \Lambda}{\left(\lambda^{3}-1\right)(\lambda+\Lambda)} \mathrm{f}
$$

where $\Lambda$ is the coefficient ratio $C_{2} / C_{1}$. E quations 14 and 16 seem not to have been presented previously. The remainder of the paper describes some tests of them and their consequences.

\section{Discussion}

A comparison of observed values for $\Delta_{\mathrm{P}, \mathrm{L}}=(\partial \mathrm{H} / \partial \mathrm{L})_{\mathrm{P}, \mathrm{T}}$ - $(\partial \mathrm{U} / \partial \mathrm{L})_{V, T}$ in natural rubber networks ${ }^{4}$ and the values calculated with eqs 8,14 , and 16 is given in Table 1 . Calculated values are plotted against the observed values in Figure 1. Agreement is evidently much better for the values from eqs 14 and 16 than those from eq 8 , the latter being consistently too small. Even though widely different stress-strain behavior is represented, as reflected by the range of $\Lambda$, the differences between results from eqs 14 and 16 are relatively minor. Values of $\mathrm{f}_{\mathrm{e}} \mathrm{f}$ calculated from the results in Table 1 are shown in Table 2. Omitting results for the smallest stretch ratio of network $A$, the averages of $f_{e} / f$ are $0.127 \pm 0.023$ for the constant-vol ume measurements. With the data from constant-pressure measurements, eqs 14 and 16 lead respectively to $f_{e} / f=0.123 \pm 0.018$ and $0.140 \pm$ 0.020, in good agreement with the constant-volume result. In addition, all three values agree well with Boyce and Treloar, ${ }^{4}$ who obtained $\mathrm{f}_{\mathrm{e}} \mathrm{ff}=0.13$, from constant-pressure torsion tests, for which the dilatation correction is much smaller. Equation 8, on the other hand, leads to a signi ficantly larger and incorrect value, $\mathrm{f}_{\mathrm{e}} / \mathrm{f}=0.189 \pm 0.018$

Values of $f_{e} / f$ from constant-pressure measurements on unswollen polyisobutylene and polyethylene networks ${ }^{11}$ are listed in Table 3. The average obtained for polyisobutylene is $-0.030 \pm 0.033$ from eq 8 and -0.094 \pm 0.033 from eq 14. An average of -0.08 was found for polyisobutylene by constant-volume measurements, ${ }^{12}$ in excellent agreement with the result from eq 14 . The average values for polyethylene are $-0.422 \pm 0.057$ from eq 8 and $-0.528 \pm 0.057$ from eq 14 . No constant-volume data are available for polyethylene, but estimates of $\kappa$ based on other methods (see below) suggest the value 
Table 1. Comparison of Observed P to V Correction Term with Predictions for Natural Rubber Networks

\begin{tabular}{|c|c|c|c|c|c|c|c|c|}
\hline network & $\phi^{\mathrm{a}}$ & $\Lambda$ & $\alpha\left(\mathrm{K}^{-1}\right) \times 10^{4}$ & $\lambda$ & $\Delta_{\mathrm{P}, \mathrm{T}}(\mathrm{obsd}), \mathrm{kPa} \mathrm{a}^{\mathrm{b}}$ & $\Delta_{\mathrm{P}, \mathrm{T}}(\mathrm{eq} 8), \mathrm{kPa}$ & $\Delta_{\mathrm{P}, \mathrm{T}}(\mathrm{eq} 14), \mathrm{kPa}$ & $\Delta_{P, T}($ eq 16), $\mathrm{kPa}$ \\
\hline A & 1.0 & 0.72 & 6.62 & 1.948 & 24.3 & 7.1 & 22.1 & 18.1 \\
\hline A & 1.0 & 0.72 & 6.62 & 1.775 & 24.2 & 8.8 & 22.2 & 18.3 \\
\hline A & 1.0 & 0.72 & 6.62 & 1.48 & 23.7 & 13.4 & 23.3 & 20.1 \\
\hline A & 1.0 & 0.72 & 6.62 & 1.08 & 30.1 & 29.5 & 32.0 & 31.0 \\
\hline B & 1.0 & 0.76 & 6.62 & 1.982 & 31.8 & 11.0 & 35.9 & 29.0 \\
\hline B & 1.0 & 0.76 & 6.62 & 1.531 & 32.4 & 19.8 & 36.9 & 31.2 \\
\hline B & 0.61 & 0.42 & 8.02 & 1.517 & 26.5 & 17.5 & 32.1 & 28.9 \\
\hline B & 0.61 & 0.42 & 8.02 & 1.342 & 27.6 & 22.9 & 33.7 & 31.2 \\
\hline B & 0.36 & 0.2 & 8.91 & 1.474 & 15.6 & 15.5 & 26.9 & 25.5 \\
\hline C & 1.0 & 0.32 & 6.62 & 1.902 & 63.6 & 23.2 & 68.8 & 62.3 \\
\hline C & 1.0 & 0.32 & 6.62 & 1.582 & 56.6 & 34.7 & 68.9 & 63.2 \\
\hline C & 1.0 & 0.32 & 6.62 & 1.18 & 71.9 & 64.3 & 78.1 & 75.2 \\
\hline D & 1.0 & 1.05 & 6.62 & 2.095 & 31.6 & 9.4 & 34.9 & 26.4 \\
\hline D & 1.0 & 1.05 & 6.62 & 1.843 & 32.0 & 12.5 & 34.4 & 26.4 \\
\hline D & 1.0 & 1.05 & 6.62 & 1.475 & 31.8 & 21.1 & 36.7 & 30.2 \\
\hline D & 1.0 & 1.05 & 6.62 & 1.213 & 47.6 & 33.6 & 42.4 & 38.3 \\
\hline D & 0.65 & 0.58 & 7.87 & 1.535 & 14.1 & 10.2 & 19.1 & 16.6 \\
\hline D & 0.39 & 0.15 & 8.80 & 1.445 & 12.9 & 12.8 & 21.3 & 20.5 \\
\hline $\mathrm{E}$ & 1.0 & 0.21 & 6.62 & 1.484 & 59.4 & 30.0 & 52.6 & 49.8 \\
\hline $\mathrm{E}$ & 1.0 & 0.21 & 6.62 & 1.377 & 53.4 & 34.4 & 52.9 & 50.5 \\
\hline $\mathrm{E}$ & 1.0 & 0.21 & 6.62 & 1.13 & 65.5 & 59.5 & 68.3 & 67.0 \\
\hline
\end{tabular}

${ }^{\mathrm{a}} \phi$ is polymer volume fraction. ${ }^{\mathrm{b}}$ Tensile force divided by initial area.

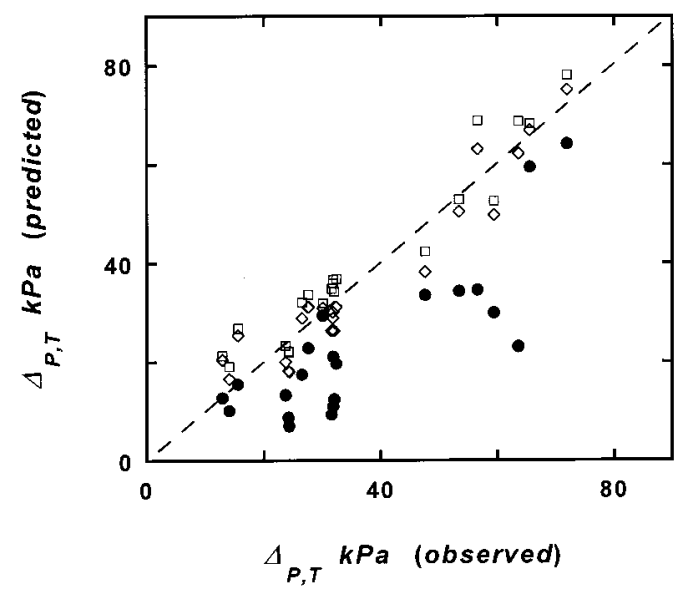

Figure 1. Comparison of predicted and observed $P \rightarrow V$ corrections for thermoelastic data on natural rubber networks. The filled circles are values calculated with eq 8, the open squares with eq 14, and the open diamonds with eq 16.

Table 2. Energetic Fraction of the Elastic Force for Natural Rubber from Constant-Volume and Corrected Constant-Pressure Measurements

\begin{tabular}{ccccccc}
\hline sample & $\phi$ & $\Lambda$ & $\lambda$ & $\mathrm{f}_{\mathrm{e}} / \mathrm{f}$ (obsd) & $\mathrm{f}_{\mathrm{e}} / \mathrm{f}$ (eq 8) & $\mathrm{f}_{\mathrm{e}} / \mathrm{f}$ (eq 14) \\
\hline A & 1.00 & 0.72 & 1.948 & 0.091 & 0.167 & 0.101 \\
A & 1.00 & & 1.775 & 0.112 & 0.188 & 0.122 \\
A & 1.00 & & 1.480 & 0.136 & 0.204 & 0.138 \\
A & 1.00 & & 1.080 & 0.089 & 0.103 & 0.038 \\
B & 1.00 & 0.76 & 1.982 & 0.139 & 0.194 & 0.128 \\
B & 1.00 & & 1.531 & 0.151 & 0.200 & 0.134 \\
B & 0.61 & 0.42 & 1.517 & 0.113 & & \\
B & 0.61 & & 1.342 & 0.137 & & \\
B & 0.36 & 0.20 & 1.474 & 0.126 & & \\
C & 1.00 & 0.32 & 1.902 & 0.137 & 0.196 & 0.129 \\
C & 1.00 & & 1.582 & 0.112 & 0.154 & 0.088 \\
C & 1.00 & & 1.180 & 0.181 & 0.218 & 0.151 \\
D & 1.00 & 1.05 & 2.095 & 0.135 & 0.192 & 0.126 \\
D & 1.00 & & 1.843 & 0.121 & 0.180 & 0.114 \\
D & 1.00 & & 1.475 & 0.120 & 0.166 & 0.099 \\
D & 1.00 & & 1.213 & 0.098 & 0.203 & 0.138 \\
D & 0.65 & 0.58 & 1.535 & 0.125 & &
\end{tabular}

from eq 14 is more nearly correct. Finally, a value of $\mathrm{f}_{\mathrm{e}} / \mathrm{f}$ has been obtained from constant-volume data for a third species, poly(dimethylsiloxane). ${ }^{13}$ The result, $\mathrm{f}_{\mathrm{e}} / \mathrm{f}$ $=+0.25$, agrees fairly well with a value from constant-

\begin{tabular}{|c|c|c|c|c|}
\hline network & $\lambda$ & $(\partial \mathrm{H} / \partial \mathrm{L})_{\mathrm{P}, \mathrm{T}} / \mathrm{f}$ & $f_{e} / f(e q 8)$ & $\mathrm{f}_{\mathrm{e}} / \mathrm{f}(\mathrm{eq} 14)$ \\
\hline \multicolumn{5}{|c|}{ Polyethylene } \\
\hline \multirow[t]{5}{*}{ PE 1} & 1.55 & 0.30 & -0.417 & -0.523 \\
\hline & 1.82 & 0.27 & -0.333 & -0.439 \\
\hline & 2.09 & 0.41 & -0.449 & -0.555 \\
\hline & 2.46 & 0.37 & -0.393 & -0.499 \\
\hline & 2.96 & 0.43 & -0.443 & -0.549 \\
\hline \multirow[t]{3}{*}{ PE2 } & 1.43 & 0.30 & -0.465 & -0.571 \\
\hline & 1.7 & 0.34 & -0.421 & -0.527 \\
\hline & 2.02 & 0.36 & -0.404 & -0.510 \\
\hline \multirow[t]{5}{*}{ PE3 } & 1.4 & 0.15 & -0.332 & -0.438 \\
\hline & 1.54 & 0.32 & -0.440 & -0.546 \\
\hline & 1.68 & 0.37 & -0.455 & -0.561 \\
\hline & 1.79 & 0.42 & -0.487 & -0.593 \\
\hline & 1.86 & 0.43 & -0.488 & -0.594 \\
\hline \multirow[t]{2}{*}{ PE 4} & 1.75 & 0.40 & -0.473 & -0.579 \\
\hline & 2.02 & 0.41 & -0.454 & -0.560 \\
\hline \multirow[t]{2}{*}{ PE5 } & 1.4 & 0.12 & -0.302 & -0.408 \\
\hline & & Polyisobut & ne & \\
\hline \multirow[t]{8}{*}{ PIB } & 1.73 & -0.01 & -0.036 & -0.100 \\
\hline & 1.78 & 0.06 & -0.101 & -0.166 \\
\hline & 2.07 & -0.03 & 0.006 & -0.059 \\
\hline & 2.32 & 0.02 & -0.037 & -0.101 \\
\hline & 2.38 & 0.01 & -0.025 & -0.090 \\
\hline & 2.52 & -0.01 & -0.003 & -0.067 \\
\hline & 3.24 & 0.01 & -0.016 & -0.080 \\
\hline & 3.75 & 0.02 & -0.024 & -0.088 \\
\hline
\end{tabular}

pressure measurements ${ }^{14}$ as corrected with eq $14, \mathrm{fe}_{\mathrm{e}} \mathrm{f}$ $=+0.20$.

Use of eq 14, based on a more accurate description of observed dilatations, has the effect of increasing $\Delta_{\mathrm{P}, \mathrm{L}}$ relative to the prediction of eq 8 and thus decreasing al gebraically the deduced value of $\mathrm{f}_{\mathrm{e}} \mathrm{f}$. I t is easily shown that

$$
\Delta f_{e} / f \equiv\left(f_{e} / f\right)_{e q ~ 14}-\left(f_{e} / f\right)_{\text {eq } 8}=-\alpha T / 3
$$

For typical temperatures $(\mathrm{T} \sim 350 \mathrm{~K})$ and expansion coefficients for polymeric liquids $\left(\alpha \sim 6 \times 10^{-4} \mathrm{~K}^{-1}\right)$,

$$
\Delta \mathrm{f}_{\mathrm{e}} \mathrm{f} \sim-0.07
$$

Accordingly, compilations of values based on eq 8 as applied to uniaxial extensions at constant pressure $\mathrm{e}^{15,16}$ 
Table 4. Comparison of $\kappa=d \ln \left\langle\mathbf{R}^{2}\right\rangle_{0} / d T$ Obtained by Various Methods

\begin{tabular}{|c|c|c|c|}
\hline \multirow[b]{2}{*}{ polymer species } & \multicolumn{3}{|c|}{$\kappa\left(\mathrm{K}^{-1}\right) \times 10^{3}$} \\
\hline & $\begin{array}{c}\text { from } \\
f_{e} / f\end{array}$ & $\begin{array}{l}\text { from } \\
\text { SANS }\end{array}$ & $\begin{array}{l}\text { from } \\
{[\eta](\mathrm{T})}\end{array}$ \\
\hline polyethylene & $-1.2^{11}(11)$ & $-1.2(22)$ & $-1.2(23)$ \\
\hline poly(ethylene-propylene) ${ }^{\mathrm{a}}$ & $-1.5(24)$ & $-1.1(25)$ & \\
\hline a-polybutene & $+0.30(26)$ & $+0.40(27)$ & \\
\hline a-polypentene & $+0.33(26)$ & & $+0.52(26)$ \\
\hline polyisobutylene & $-0.25(12)$ & & $-0.28(28)$ \\
\hline 8\% vinyl polybutadiene & $+0.16(29)$ & & $\sim 0(30)$ \\
\hline high cis-polyisoprene ${ }^{b}$ & $+0.41(7)$ & $+0.40(21)$ & \\
\hline poly(dimethylsiloxane) & $+0.78(13)$ & & $+0.71(14)$ \\
\hline a-polystyrene & $+0.17(31,32)$ & $\sim 0$ (33) & \\
\hline $\begin{array}{l}\text { a-poly(methyl } \\
\text { methacrylate) }\end{array}$ & $-0.10(34)$ & $+0.10(33)$ & \\
\hline poly(oxyethylene) & $+0.03(35)$ & $-0.30(36)$ & $+0.2(37)$ \\
\hline
\end{tabular}

a The $f_{e} / f$-based value was obtained with a $\sim 1: 1$ statistical copolymer of ethylene and propylene; the SANS-based value was obtained with an alternating copolymer (fully saturated low 3,4polyisoprene). ${ }^{b}$ The $f_{e} / f$-based value was obtained with natural rubber; the SANS-based value was obtained with anionically polymerized isoprene ( $70 \%$ cis, $20 \%$ trans, $10 \% 3,4)$.

can be easily corrected, either with eq 17 if the thermal expansion coefficient is known or with eq 18 if not.

The molecular interpretation of $f_{e} / f$, based on the Gaussian network model, was made possible by the demonstration that the force-deformation relationship for random coils is universal.17,18 For a Gaussian network, the force-temperature relationship at constant volume can be expressed as

$$
f(T) \propto T /\left\langle R^{2}\right\rangle_{0}
$$

where $\left\langle R^{2}\right\rangle_{0}$ is the mean-square end-to-end distance for unperturbed free chains of the network species at the test temperature. Thus, assuming no other contribution to the restoring force, eq 3 leads immediately to the result 18,19

$$
\kappa=\frac{f_{e} / f}{T}
$$

Accordingly, the correction from values of $\kappa$ obtained with eq 8 to those corresponding to the more nearly correct eq 14 is

$$
\Delta \kappa=-\alpha / 3
$$

or with the typical polymeric liquids value, $\alpha=6 \times 10^{-4}$ $\mathrm{K}^{-1}$,

$$
\Delta \kappa \sim-0.2 \times 10^{-3} \mathrm{~K}^{-1}
$$

Some comparisons of $\kappa$ obtained from $\mathrm{f}_{\mathrm{e}} \mathrm{f}$ data with those obtained from size vs temperature data from small-angle neutron scattering are shown in Table 4. Also included are values of $\kappa$ inferred from the temperature dependence of intrinsic viscosity in good solvents on the assumption of athermal solvent behavior. ${ }^{1} \mathrm{We}$ omit comparisons with values obtained with RIS calculations, ${ }^{1}$ which involve adjustable parameters, and with multiple $\Theta$ solvent data, which are known to be undependable. ${ }^{20,21}$ When available, the listed values of $\kappa$ from $f_{e} / f$ are those cal culated directly from constantvolume measurements with eq 20 . Such values were available for high cis-polyisoprene (natural rubber), polyisobutylene, and poly(dimethylsiloxane), as discussed earlier. The others were obtained from uniaxial extension measurements at constant pressure, as cor- rected for dilatation with eq 8 . Those literature values were then corrected by applying either eq 21 or eq 22 to obtain the values in the table.

The results in Table 4 demonstrate a fair agreement in corrected $\kappa$ among the various methods. For polyethylene, the value of $\kappa$ based on eq 8 is -1.0 , while that based on eq 14 is -1.2 , a value in significantly better agreement with values from the other two methods. The two available results for poly(ethylene-propylene) are rather different, but that may be due in part to sequencing differences in the polymers. The various methods agree roughly that $\kappa$ for atactic polystyrene, for poly(methyl methacrylate), and for low vinylpolybutadiene is effectively zero. Values from $\mathrm{f}_{\mathrm{e}} / \mathrm{f}$ and SANS are generally consistent for all cases except polyoxyethylene, in which the disagreement may be beyond the errors.

\section{Concluding Remarks}

The dilatation predictions, the comparisons we have presented of $\mathrm{f}_{\mathrm{e}} / \mathrm{f}$ obtained by the constant-volume method and the constant-pressure method, and the improved agreement of $\kappa$ for polyethylene all support the Gee formula, eq 9, and its thermodynamic consequence, eq 14. This is a useful outcome in that it removes a puzzling inconsistency in the thermoel astic analysis of polymeric elasticity. It should be noted, however, that the changes that result from the use of eq 14 are not large and that the conclusions we have drawn from the results in Table 4 would not be materially changed if eq 8 had been used. It should also be noted that eq 9 remains strictly empirical and that, in our hands at least, it remains something of a puzzle: despite its attractive simplicity, we have been unable to derive it from a general mechanical principle.

Acknowledgment. We thank Buckley Crist for a very helpful discussion of polymeric thermoelasticity and its molecular significance. We also thank Colin Price and Geoffrey Allen for their encouragement. Finally, we express our admi ration for the magnificent body of data that made this work possible.

\section{References and Notes}

(1) Flory, P. J . Statistical Mechanics of Chain Molecules; WileyInterscience: New York, 1969.

(2) J ames, H. M.; Guth, E. J . Chem. Phys. 1943, 11, 531.

(3) Price, C. Proc. R. Soc. London, A 1976, 351, 331.

(4) Treloar, L. R. G. The Physics of Rubber Elasticity, 3rd ed.; Clarendon Press: Oxford, 1975.

(5) Allen, G.; Kirkham, M. J .; Padget, J .; Price, C. Trans. Faraday Soc. 1971, 67, 1278.

(6) Allen, G.; Bianchi, U.; Price, C. Trans. Faraday Soc. 1963, 59,2493

(7) Flory, P. J . Trans. Faraday Soc. 1961, 57, 829.

(8) Gee, G.; Stern, J .; Treloar, L. R. G. Trans. Faraday Soc. 1950, 46, 1101.

(9) Christensen, R. G.; Hoeve, C. A. J . J . Polym. Sci., Part A-1 1970, 8, 1503.

(10) Gee, G. Trans. Faraday Soc. 1946, 42, 585.

(11) Ciferri, A.; Hoeve, C. A. J .; Flory, P. J . J . Am. Chem. Soc. 1961, 83, 1015.

(12) Allen, G.; Gee, G.; Kirkham, G.; Price, C.; Padget, J . C. J . Polym. Sci., Part C 1968, 23, 201.

(13) Price, C.; Padget, J . C.; Kirkham, M. J .; Allen, G. Polymer 1969, 10, 1278 .

(14) Mark, J . E.; Flory, P. J . J . Am. Chem. Soc. 1964, 86, 138.

(15) Mark, J. E. Rubber Chem. Technol. 1973, 46, 593. 
(16) Mark, J . E. J . Polym. Sci., Macromol. Rev. 1976, 11, 135.

(17) Volkenstein, M. V.; Ptitsyn, O. B. Zh. Tekh. Fiz. 1955, 25, 662. See also pp 501-507 in: Volkenstein, M. V. Configurational Statistics of Polymeric Chains; Interscience: New York, 1963.

(18) Flory, P. J .; Hoeve, C. A. J .; Ciferri, A. J . Polym. Sci. 1959, 34, 337.

(19) Ptitsyn, O. B. Fiz. Tverdogo Tela 1959, 25, 662.

(20) Bianchi, U. J . Polym. Sci., Part A 1964, 2, 3083.

(21) Krishnamoorti, R.; Graessley, W. W.; Zirkel, A.; Richter, D.; Fetters, L. J .; Lohse, D. J . J . Polym. Sci., Polym. Phys. Ed., submitted.

(22) Boothroyd, A. T.; Rennie, A. R.; Boothroyd, C. B. Eur. Phys. Lett. 1991, 15, 715

(23) Flory, P. J .; Ciferri, A.; Chiang, R. J . Am. Chem. Soc. 1961 83, 1023.

(24) Mark, J. E. J . Chem. Phys. 1972, 57, 2541. Mark, J . E. J . Polym. Sci. 1974, 12, 1207.

(25) Zirkel, A.; Richter, D.; Pyckhout-Hintzen, W.; Fetters, L. J Macromolecules 1992, 25, 954.

(26) Mark, J . E.; Flory, P. J . J . Am. Chem. Soc. 1965, 87, 1423.
(27) Zirkel, A.; Urban, V.; Richter, D.; Fetters, L.J .; Huang, J . S.; Kammpmann, R.; Hadjichristidis, N. Macromolecules 1992, 25, 6148.

(28) Mark, J . E.; Thomas, G. B. J . Phys. Chem. 1966, 70, 3588.

(29) Mark, J . E.; Llorente, M. A. Polym. J . 1981, 13, 543.

(30) Mays, J. W.; Hadjichristidis, N.; Graessley, W. W.; Fetters, L. J. J Polym. Sci., Polym. Phys. Ed. 1986, 24, 2553.

(31) Orofino, T. A.; Ciferri, A. J . Phys. Chem. 1964, 68, 3136.

(32) Dusek, K. Collect. Czech. Chem. Commun. 1966, 31, 1893; 1967, 32, 2264.

(33) Boothroyd, A.; Rennie, A. R.; Wignall, G. D. J . Chem. Phys. 1993, 99, 9135.

(34) Ciferri, A. J . Polym. Sci., Part A 1964, 2, 3089.

(35) Mark, J . E.; Flory, P. J . J . Am. Chem. Soc. 1965, 87, 1415.

(36) Smith, G. D.: Yoon, D. Y.: Jaffe, R. L.; Colby, R. H. Krishnamoorti, R.; Fetters, L. J . Macromolecules 1996, 29, 3462.

(37) Bluestone, S.; Mark, J . E.; Flory, P. J . ACS Polym. Prepr. $1974,15,520$.

MA010989P 